\title{
Prosocial effects of oxytocin in two mouse models of autism spectrum disorders
}

\author{
Brian L. Teng ${ }^{a, d}$, Randal J. Nonneman ${ }^{a, c}$, Kara L. Agster ${ }^{a, b}$, Viktoriya D. Nikolovaa,b, \\ Tamara T. Davis $^{\mathrm{a}, \mathrm{d}}$, Natallia V. Riddick ${ }^{\mathrm{a}, \mathrm{b}}$, Lorinda K. Baker ${ }^{\mathrm{a}}$, Cort A. Pedersen ${ }^{\mathrm{a}, \mathrm{b}}$, Michael \\ B. Jarstfer ${ }^{a, d}$, and Sheryl S. Moy ${ }^{a, b}$ \\ ${ }^{a}$ Carolina Institute for Developmental Disabilities, University of North Carolina School of Medicine, \\ Chapel Hill, NC 27599, USA \\ ${ }^{b}$ Department of Psychiatry, University of North Carolina School of Medicine, Chapel Hill, NC \\ 27599, USA \\ 'Department of Genetics, University of North Carolina School of Medicine, Chapel Hill, NC 27599, \\ USA \\ dUNC Eshelman School of Pharmacy, University of North Carolina, Chapel Hill, NC 27599, USA
}

\begin{abstract}
Clinical evidence suggests that oxytocin treatment improves social deficits and repetitive behavior in autism spectrum disorders (ASDs). However, the neuropeptide has a short plasma half-life and poor ability to penetrate the blood-brain barrier. In order to facilitate the development of more bioavailable oxytocinergic compounds as therapeutics to treat core ASD symptoms, small animal models must be validated for preclinical screens. This study examined the preclinical utility of two inbred mouse strains, BALB/cByJ and C58/J, that exhibit phenotypes relevant to core ASD symptoms. Mice from both strains were intraperitoneally administered oxytocin, using either acute or sub-chronic regimens. Acute oxytocin did not increase sociability in BALB/cByJ; however, sub-chronic oxytocin had significant prosocial effects in both BALB/cByJ and C58/J. Increased sociability was observed 24 hours following the final oxytocin dose in BALB/cByJ, while prosocial effects of oxytocin emerged 1-2 weeks post-treatment in C58/J. Furthermore, acute oxytocin decreased motor stereotypy in C58/J and did not induce hypoactivity or anxiolytic-like effects in an open field test. This study demonstrates that oxytocin administration can attenuate social deficits and repetitive behavior in mouse models of ASD, dependent on dose regimen and genotype. These findings provide validation of the BALB/cByJ and C58/J models as useful platforms for screening novel drugs for intervention in ASDs and for elucidating the mechanisms contributing to the prosocial effects of oxytocin.
\end{abstract}

\section{Keywords}

oxytocin; autism models; drug discovery; repetitive behavior; sociability; stereotypy

\section{(C) 2013 Elsevier Ltd. All rights reserved.}

Corresponding Author: Brian L. Teng, UNC Eshelman School of Pharmacy, Division of Chemical Biology and Medicinal Chemistry, University of North Carolina, 308 Beard Hall, Campus Box 7568, Chapel Hill, NC 27599-7568, USA; Phone: (919) 966-8654; BrianLTeng@unc.edu.

Publisher's Disclaimer: This is a PDF file of an unedited manuscript that has been accepted for publication. As a service to our customers we are providing this early version of the manuscript. The manuscript will undergo copyediting, typesetting, and review of the resulting proof before it is published in its final citable form. Please note that during the production process errors may be discovered which could affect the content, and all legal disclaimers that apply to the journal pertain. 


\section{Introduction}

Autism spectrum disorders (ASDs), which occur in approximately $1 \%$ of the population, are characterized by core deficits in sociability and communication skills, as well as abnormal restrictive and repetitive behaviors (CDC, 2012; Elsabbagh et al., 2012; Nazeer and Ghaziuddin, 2012). Although clinical evidence suggests that some medications may alleviate repetitive behavior in ASDs (e.g. atypical antipsychotics and selective serotonin reuptake inhibitors), these drugs have not proven to be consistently effective and have been associated with significant adverse side effects (Carrasco et al., 2012; McDougle et al., 2005; McPheeters et al., 2011; Stachnik and Nunn-Thompson, 2007). Furthermore, there are no pharmacological interventions for treating the social deficits associated with ASDs; however, the oxytocin signaling pathway is emerging as a promising avenue for ASD drug discovery efforts (Meyer-Lindenberg et al., 2011; Striepens et al., 2011).

Oxytocin is a neuropeptide hormone with a long recognized role in maternal responses, but there is increasing evidence that oxytocin mediates other aspects of social behavior, and that disruption of normal oxytocin function could lead to impaired sociability and affiliative interactions (Insel, 2010). In line with this premise, several reports indicate oxytocin signaling may be deficient in ASDs (Higashida et al., 2012; Striepens et al., 2011). Thus, pharmacological activation of central oxytocin receptors could have beneficial effects on core ASD symptoms, especially social deficits. This hypothesis is supported by studies that demonstrate acute high doses of oxytocin can improve social function and reduce repetitive behavior in individuals with ASD (Andari et al., 2010; Guastella et al., 2010; Hollander et al., 2007; Hollander et al., 2003). However, the clinical utility of oxytocin is limited by its short half-life, poor ability to cross the blood-brain barrier, and affinity for vasopressin receptors (Chini and Manning, 2007; Kang and Park, 2000; Morin et al., 2008; SchorscherPetcu et al., 2010). These concerns underscore the need to explore the development of selective, non-peptide drugs to target the oxytocin pathway. To achieve this goal, appropriate small animal models are critical for preclinical efficacy testing of novel oxytocinergic compounds.

Previously, we screened multiple commercially-available inbred mouse strains for abnormal phenotypes relevant to core symptoms of human developmental disorders, and identified strains that could serve as appropriate behavioral models for ASDs (Moy et al., 2004; Moy et al., 2008; Moy et al., 2007). For example, we found that specific strains have deficient sociability in a three-chambered choice task, which measures the time a test mouse spends in proximity to a stranger mouse versus an empty cage (i.e. non-social object) (Moy et al., 2008; Moy et al., 2007; Nadler et al., 2004). One of these strains, BALB/cByJ, exhibited both a lack of social preference and high levels of anxiety-like behavior, which could reflect the comorbid anxiety frequently observed in ASDs (Brodkin, 2007). BALB/cJ, a related sub-strain, also has impaired sociability in a three-chambered choice task (Brodkin et al., 2004; Sankoorikal et al., 2006), as well as deficient ultrasonic vocalization during social interaction, which may be relevant to core communication deficits observed in ASDs (Kikusui et al., 2011; Panksepp et al., 2007).

$\mathrm{C} 58 / \mathrm{J}$ is another inbred mouse strain that shows low sociability in the three-chambered choice task (Moy et al., 2008; Ryan et al., 2010). C58/J mice also have deficits in social transmission of food preference, a test used to model social communication, and exhibit overt, abnormal repetitive behavior (Ryan et al., 2010). At an early age, C58/J mice spontaneously develop motor stereotypies, which include backflipping, "jackhammer" jumping, and upright scrabbling (Ryan et al., 2010). These robust ASD-like phenotypes in social and repetitive behaviors make the $\mathrm{C} 58 / \mathrm{J}$ strain an attractive model for the preclinical evaluation of drug candidates to treat autism. Thus far, one study has identified an agent 
(GRN-529, a negative allosteric modulator of the metabotropic glutamate receptor subtype 5) that has efficacy in reducing the repetitive behavior of C58/J mice, but the study did not examine drug effects on the lack of sociability in this strain (Silverman et al., 2012b).

Overall, the oxytocin receptor is among the most promising targets for intervention in ASDs, which highlights the need for translational models to assess the behavioral pharmacology of therapeutics targeting the oxytocin pathway (including oxytocin itself). In the present studies, we utilized BALB/cByJ and C58/J to evaluate the effects of oxytocin treatment on behavioral phenotypes relevant to core ASD symptoms. Using both inbred strains allowed the identification of prosocial oxytocin effects that were dependent on genetic background, and the ability to investigate oxytocin efficacy against aberrant repetitive behavior in $\mathrm{C} 58 / \mathrm{J}$.

\section{Methods and Materials}

\subsection{Animals}

For the BALB/cByJ model, cohorts of male mice (3-4 weeks old, $n=12-24$ ) were obtained from Jackson Laboratory (JAX; Bar Harbor, ME). For the C58/J model, mice were offspring of $\mathrm{C} 58 / \mathrm{J}$ breeding pairs (JAX) weaned at postnatal day 21 and caged with same-sex littermates. Dams were fed ProLab RMH 2000 and all other mice were fed ProLab RMH 3000 ad libitum with free access to water. Mice were maintained in groups of 2-4 animals per polycarbonate mouse cage lined with Bed-o' Cobs bedding. For enrichment, each cage contained a small section of PVC pipe and two nestlet squares. Mice were housed in an animal facility at The University of North Carolina at Chapel Hill (UNC) in a room with a 12-hour light/dark cycle (lights off at $7 \mathrm{pm}$ ). All animal care and procedures were conducted in strict compliance with the animal welfare policies set by the National Institutes of Health and UNC, and were approved by the UNC Institutional Animal Care and Use Committee.

\subsection{Drug treatment}

Oxytocin (Bachem, Torrance, CA) was dissolved in saline containing $0.002 \%$ acetic acid. For acute treatments, mice were given a single intraperitoneal (IP) injection of vehicle or 1.0 $\mathrm{mg} / \mathrm{kg}$ oxytocin 50 minutes prior to testing for sociability (BALB/cByJ model; Fig. 1), or for repetitive behavior (C58/J model). For sub-chronic treatments (both models), mice were given four IP injections of vehicle or $1.0 \mathrm{mg} / \mathrm{kg}$ oxytocin across $8-9$ days, with at least 48 hours between each injection; behavioral tests occurred approximately 24 hours after the last injection (Fig. 1). This sub-chronic regimen was designed to reduce the stress that might be found with daily injections, while enhancing sensitivity to oxytocin, as observed with other drugs (Fiorino and Phillips, 1999; Moy and Breese, 2002). Considering the pharmacokinetic properties of oxytocin, many groups have used intracerebroventricular (ICV) injection for acute oxytocin treatments; however, this route induces significant stress and sometimes requires anesthesia in mice, which could interact with oxytocin effects and would not be ideal for repeated administration (Kim et al., 1998; Yamakage et al., 2002). The IP route of administration was selected for rapid drug absorption and relatively minimal stress for the animals. Importantly, other groups have shown that acute IP injection of $1.0 \mathrm{mg} / \mathrm{kg}$ oxytocin in mice has antidepressant-like, anti-nociceptive, and autonomic nervous system effects, suggesting that oxytocin is able to enter the central nervous system by this method (Arletti and Bertolini, 1987; Lundeberg et al., 1994; Ring et al., 2006). Experimenters blind to drug identity performed all injections and behavioral tests during daytime (light phase) hours (10am-4pm).

\subsection{Behavioral tests}

2.3.1 BALB/CByJ model-Effects of acute and sub-chronic oxytocin on social preference in the three-chambered choice task were evaluated in separate cohorts of male mice, 6-8 
weeks of age at time of testing. The study focused on male mice, in accordance with the higher incidence of autism observed in male versus female children. BALB/cByJ Cohort 1 ( $n=6$ per treatment group; 6-7 weeks of age) was tested for acute oxytocin effects on sociability in the three-chambered choice task (Fig. 1). Two separate BALB/cByJ cohorts were tested following sub-chronic oxytocin treatment: Cohort 2 ( $n=12$ per treatment group; $8-9$ weeks of age at time of testing) and Cohort $3(n=15-18$ per treatment group; 7-8 weeks of age at time of testing) were each tested in the three-chambered choice task approximately 24 hours following the final dose of vehicle or oxytocin (Fig. 1).

2.3.2 C58/J model-Male and female mice (15-16 of each sex per treatment group; 7-8 weeks of age at time of testing) were used to evaluate the effects of sub-chronic oxytocin treatment on both social preference and repetitive behavior. Both male and female C58/J mice were included in this study, because each displays profound ASD-relevant phenotypes (Ryan et al., 2010), and were available from in-house breeding. For the sociability study, all mice were tested approximately 24 hours following the sub-chronic oxytocin regimen. In order to evaluate possible long-term effects of sub-chronic oxytocin exposure, half of the mice were re-tested for sociability 1 week after the final injection (C58/J Cohort 1$)$, and the remaining mice were re-tested 2 weeks after the final injection (C58/J Cohort 2) (Fig. 1). Test groups were balanced as much as possible for treatment and sex. C58/J Cohort 1 (6-8 per treatment group per sex) was further assessed for repetitive behavior 3-4 hours following the sociability test at the 24-hour and 1-week time points (Fig. 1).

C58/J Cohort 3 (11 males and 10 females; 4-6 months in age) was evaluated for acute oxytocin effects on repetitive behavior using a crossover study design. This crossover design was executed such that half of the mice received vehicle while the other half received oxytocin for the first test, then one week later, the reverse treatments were given for a second test. Thus, each mouse was given two tests, one with vehicle pretreatment and one with oxytocin pretreatment, with one week between the tests. In order to determine the acute effects of oxytocin on general activity, C58/J Cohort 4 (8 males and 8 females; 4-5 months in age) was tested in an open field test, using the same crossover design.

\subsection{Three-chambered choice test}

Social approach was assessed using an automated three-chambered box (Moy et al., 2007; Nadler et al., 2004) with retractable doorways in each dividing wall to allow entry into each chamber. Entries and time spent in each chamber of the social text box were measured by photocells embedded in each doorway. The choice test had two 10-minute phases. The first phase was habituation - the test mouse was first placed in the middle chamber, then the doorways were opened to the side chambers (empty) in order to allow 10 minutes of free exploration. The second phase was sociability - after the habituation period, the test mouse was enclosed in the center compartment of the social test box, then an unfamiliar stranger (a sex-matched C57BL/6J adult mouse) was placed in a wire cage in one side chamber, while an empty wire cage was placed in the other side. The stranger mouse's location was alternated between the left and right chambers of the social test box across subjects. The doors were then reopened, and the subject was allowed to explore the entire social test box for 10 minutes. Measures were taken of the time spent in each chamber and number of entries into each chamber by the automated testing system. In addition, a human observer scored time spent sniffing each wire cage, using previously described software (Johns et al., 1998).

\subsection{Repetitive behavior in $\mathrm{C} 58 / \mathrm{J}$}

To assess repetitive behavior, each subject was placed into a clean home cage and video recorded for 20 minutes (acute regimen) or 30 minutes (sub-chronic regimen). The videos 
were scored for motor stereotypy, grooming, and locomotion using Observer XT (Noldus Information Technology, Leesburg, VA). Two types of motor stereotypy were scored: jackhammer jumping and backflipping, as previously defined (Ryan et al., 2010). These behaviors were selected as the predominant forms exhibited by C58/J (Ryan et al., 2010). Locomotion was coded during bouts of ambulation in which the animal took at least 3 steps (with not more than 1 second between steps). The total numbers of jumps and backflips were combined for the motor stereotypy score, while grooming and locomotion were scored for duration.

\subsection{Open field activity}

Activity was assessed immediately following oxytocin or vehicle treatment in a 2-hour test in a photocell-equipped automated open field $(41 \mathrm{~cm} \times 41 \mathrm{~cm} \times 30 \mathrm{~cm}$; Versamax System, AccuScan Instruments, Columbus, $\mathrm{OH}$ ). Parameters included total distance and time spent in the center region of the chamber. Activity chambers were contained inside soundattenuating boxes, equipped with ceiling lights and fans.

\subsection{Statistical analysis}

Data were analyzed using StatView software (SAS, Cary, NC). For the BALB/cByJ model, groups were compared with repeated measures analysis of variance (ANOVA), with factors treatment, cohort group (for the sub-chronic regimen), and side of social test box. For the C58/J model, data from the social task were analyzed with repeated measures ANOVAs, with factors treatment, sex, time of test, and side of social test box. Separate repeated measures ANOVAs were conducted for each sex to determine oxytocin effects on sociability in male and female mice. Within-treatment repeated measures ANOVAs were used to determine social preference. Activity data were analyzed with repeated measures ANOVAs, with factors treatment, sex, and time (5-minute intervals across a 2-hour test). For all comparisons, significance was set at $\mathrm{p}<0.05$.

\section{Results}

\subsection{Oxytocin effects in the BALB/cByJ model}

We previously reported low sociability in adolescent male BALB/cByJ mice (Moy et al., 2007). Considering the established connection between oxytocin and social behavior, we predicted that oxytocin would rescue this deficit in sociability. Surprisingly, we found that acute treatment with oxytocin failed to induce significant social preference (Fig. 2A) or increase exploration (Fig. 2B) in BALB/cByJ Cohort 1. Because acute oxytocin treatment lacked prosocial efficacy, and other behavioral studies have shown beneficial effects of repeated oxytocin administration (Bowen et al., 2011; Cushing and Carter, 2000), we next tested a sub-chronic oxytocin regimen. Following a sub-chronic regimen, two cohorts of mice (BALB/cByJ Cohorts 2 and 3 ) treated with oxytocin demonstrated a significant preference for social proximity in a three-chambered choice task, conducted 24 hours following the final dose of oxytocin (Fig. 3). A repeated measures ANOVA on time spent in each side chamber by the two cohort groups revealed a highly significant main effect of side $[F(1,53)=7.72, p=0.0075]$, and a treatment $x$ side interaction that approached significance $[F(1,53)=3.34, p=0.0731]$ (Fig. 3A-B). Oxytocin also led to a significant preference for sniffing directed towards the cage containing the stranger mouse, versus the empty wire cage, in both cohort groups [within-treatment comparisons following significant main effect of side, $\mathrm{F}(1,51)=8.61, \mathrm{p}=0.005$, and treatment $\mathrm{x}$ side interaction, $\mathrm{F}(1,51)=4.59, \mathrm{p}=0.037$ ] (Fig. 3C-D). Mice given sub-chronic exposure to oxytocin showed a small increase in number of entries during the test [treatment $x$ side interaction, $F(1,53)=4.81, p=0.0327$ ], although post-hoc comparisons were not significant (Fig. 3E-F). No significant effects of cohort were found for any measure. 


\subsection{Prosocial oxytocin effects in the $\mathrm{C} 58 / \mathrm{J}$ model}

Previous work in our laboratory has shown that both male and female C58/J mice exhibit social deficits, as well as overt repetitive behavior (Moy et al., 2008; Ryan et al., 2010). Because the acute oxytocin treatment did not have significant prosocial effects in the BALB/ cByJ model, we only tested C58/J mice with the sub-chronic regimen. In contrast to our findings in $\mathrm{BALB} / \mathrm{cByJ}$, sub-chronic treatment with oxytocin in $\mathrm{C} 58 / \mathrm{J}$ did not reverse lack of social preference 24 hours following the final drug dose (Fig. 4). However, one study has shown that prosocial effects of repeated oxytocin administration can be observed up to 13 days post-treatment (Bowen et al., 2011). Thus, C58/J mice were given a second social approach test, with half of the mice retested 1 week after sub-chronic oxytocin treatment (C58/J Cohort 1), and half of the mice retested 2 weeks after treatment (C58/J Cohort 2). Strikingly, significant prosocial oxytocin effects emerged in these follow-up tests [withintreatment comparisons following significant main effect of side, $F(1,56)=11.96, p=0.001$; treatment $\mathrm{x}$ side interaction, $\mathrm{F}(1,56)=7.19, \mathrm{p}=0.0096$; and main effect of sex, $\mathrm{F}(1,56)=4.03$, $\mathrm{p}=0.0497$; no significant effect of week]. Notably, there were no effects of retest (week of testing) on side preference in the vehicle treatment groups.

Separate repeated measures ANOVAs were conducted for the male and female groups to determine whether the prosocial efficacy of oxytocin was dependent upon sex. In the male mice, significant sociability was observed in the oxytocin-treated group retested at the 2week, but not the 1-week, time point [main effect of side, $\mathrm{F}(1,28)=4.98$, $\mathrm{p}=0.0339$; and main effect of week, $F(1,28)=6.59, \mathrm{p}=0.0159$ ] (Fig. 4A). In contrast, strong preference for spending time in the side with the stranger mouse was observed in the oxytocin-treated female groups at both time points [main effect of side, $\mathrm{F}(1,28)=7.05$, $\mathrm{p}=0.0129$; and treatment $\mathrm{x}$ side interaction, $\mathrm{F}(1,28)=8.21, \mathrm{p}=0.0078$; no significant effect of week] (Fig. 4B).

We have previously found that the measure of time spent sniffing the wire cages is not as robust an index for social deficits as time spent in each side chamber (Moy et al., 2008; Ryan et al., 2010). In the present study, repeated measures ANOVAs did not identify any significant treatment effects on sniffing in either the male or female groups (Fig. 5). However, it is notable that none of the male mice treated with vehicle demonstrated significant preference for sniffing at the stranger cage, while the oxytocin-treated male mice had overt sniffing preference for the social stimulus, albeit only at the 1-week time point [post-hoc tests following main effect of side, $F(1,28)=13.65$, $\mathrm{p}=0.0009$ ] (Fig. 5A). In contrast, both the vehicle and oxytocin groups of female mice showed significant social preference 24 hours after the last dose of the drug regimen [main effect of side, $\mathrm{F}(1,30)=14.46, \mathrm{p}=0.0007]$ (Fig. 5B). At the 1-week time point, only the oxytocin-treated female group still demonstrated sniffing preference for the stranger cage [main effect of side, $\mathrm{F}(1,28)=11.9, \mathrm{p}=0.0018]$.

Lastly, there was a significant effect of retest on the numbers of entries, indicating that the amount of exploration in the social approach test changed with acclimation to the task [main effect of test, $F(1,55)=106.57$, $\mathrm{p}<0.0001]$. However, the sub-chronic oxytocin regimen did not have any effects on this measure (Fig. 6), suggesting that the increased sociability was not due to a general increase in activity during the test.

\subsection{Oxytocin and repetitive behavior in the $\mathrm{C} 58 / \mathrm{J}$ model}

In addition to social and communication deficits, the C58/J strain provides a model of abnormal repetitive behavior, relevant to the core diagnostic indicators for autism (Moy et al., 2008; Ryan et al., 2010). In the present study, the effects of both acute (C58/J Cohort 3) and sub-chronic (C58/J Cohort 1) oxytocin treatment were evaluated against motor 
stereotypy (backflipping and repeated jumping), a lower-order form of repetitive behavior (Fig. 7). Because no significant effects of sex were determined for stereotypy following either dosing regimen, data for male and female mice were combined. As shown in Fig. 7A, an acute single-dose of oxytocin $(1.0 \mathrm{mg} / \mathrm{kg})$ decreased levels of repetitive behavior, with significant effects emerging in the last 10 minutes of the recording session [post-hoc comparisons following main effect of treatment, $\mathrm{F}(1,15)=11.26$, $\mathrm{p}=0.0043$; and time, $\mathrm{F}(1,15)=11.54, \mathrm{p}=0.004]$. This dose also decreased locomotion across the first and second halves of the recording session [main effect of treatment, $\mathrm{F}(1,15)=19.41, \mathrm{p}=0.0005$; and time, $\mathrm{F}(1,15)=9.35, \mathrm{p}=0.008$ ] (Fig. 7B). However, levels of grooming were increased by oxytocin [main effect of treatment, $\mathrm{F}(1,15)=9.01, \mathrm{p}=0.009$ ], indicating that the neuropeptide did not induce general decreases in all behaviors (Fig. 7C). Sub-chronic treatment with oxytocin did not have any persistent effects on motor stereotypy, locomotion, or grooming in the C58/J mice (Fig. 7D-F).

Although the results from the acute regimen showed that oxytocin could significantly reduce aberrant repetitive behavior, the concomitant decrease in locomotion indicated that acute oxytocin might also have sedative-like effects. Therefore, the effects of oxytocin on general activity levels were examined in C58/J Cohort 4 (Fig. 8). Because repeated measures ANOVAs did not reveal significant effects of sex on measures from the activity test, data from male and female mice were combined. As shown in Fig. 8A, there were no significant effects of oxytocin on locomotion in an open field test across a 2-hour session. Furthermore, oxytocin did not increase time spent in the center regions, suggesting the neuropeptide did not have anxiolytic-like effects in C58/J (Fig. 8B).

\section{Discussion}

This study provided the first evidence that peripherally administered oxytocin could reverse the social deficits exhibited by two mouse models with face validity to core ASD symptoms (i.e. BALB/cByJ and C58/J mice). We also observed that exogenous oxytocin could attenuate motor stereotypy in $\mathrm{C} 58 / \mathrm{J}$ mice, at a dose that did not induce statistically significant hypoactivity in an open field test. Importantly, the ability of oxytocin to influence these ASD-like behaviors was critically dependent on the dosage regimen (i.e. sub-chronic but not acute oxytocin could improve social deficits, and vice versa for repetitive behavior in C58/J). Our preclinical findings complement clinical studies that demonstrate the beneficial effects of oxytocin in ASD subjects, and demonstrate the importance of treatment regimen, genotype, and sex in modulating oxytocin efficacy.

To date, most clinical studies have only tested acute single-dose oxytocin treatment in ASDs. For example, Hollander and colleagues found that oxytocin infusion improved social cognition and reduced repetitive behavior in ASD subjects (Hollander et al., 2007; Hollander et al., 2003). Two other studies determined that acute intranasal oxytocin improved emotion recognition in young ASD subjects (ages 12-19), and led to increased eye gaze and more appropriate social behavior in high-functioning ASD subjects (Andari et al., 2010; Guastella et al., 2010). More recently, a 6-week randomized controlled trial of twice daily intranasal oxytocin in adults with ASD demonstrated efficacy on social perception and quality of life, and a trend for improvement in lower-order repetitive behavior (Anagnostou et al., 2012). Although this longer-term study showed that daily oxytocin is well tolerated and has therapeutic potential, the treatment did not have efficacy in the primary outcome measures of social cognition/function or higher-order repetitive behavior. Interestingly, clinical studies in schizophrenia (another disorder characterized by social deficits) found improvement in symptoms, including social cognition, after 2-3 weeks of daily intranasal oxytocin administration (Feifel et al., 2010; Pedersen et al., 2011). Overall, these clinical studies support oxytocin as a promising intervention, but further work 
is necessary to determine optimal treatment regimens and limiting factors for therapeutic efficacy. Considering the genetic heterogeneity in the human population and the differential prosocial efficacy of oxytocin treatment in BALB/cByJ and C58/J, genetic background is likely to be an important factor in modulating oxytocin response in individuals with ASD.

In the C58/J model, the sub-chronic oxytocin regimen induced prosocial effects that emerged 1-2 weeks following treatment, dependent on sex. In particular, significant sociability emerged 2 weeks post-treatment in male C58/J mice, but was observed at the 1week and 2-week post-treatment time points in female $\mathrm{C} 58 / \mathrm{J}$ mice. These relatively longterm effects of sub-chronic oxytocin on social behavior are consistent with findings from Bowen and colleagues showing that 10 days of once-daily oxytocin $(1 \mathrm{mg} / \mathrm{kg}$, IP) modestly improved sociability in rats after a 13-day washout period (Bowen et al., 2011). Although the neurobiology underlying the prosocial effects of sub-chronic oxytocin treatment remains to be elucidated, one contributing mechanism may be the up-regulation of the endogenous oxytocin system within the hypothalamus (e.g. increased oxytocin receptor gene expression and oxytocin secretion) with repeated exposures (Bowen et al., 2011). Another study has suggested that strong, chronic stimulation of the oxytocin system promotes the reversible structural plasticity/remodeling of oxytocinergic neurons and their associated glial cells in adult hypothalamus, leading to altered function and increased oxytocin secretion (Theodosis, 2002). Moreover, ovarian hormones stimulate hypothalamic oxytocin and oxytocin receptor expression, and enhance the electrical activity of oxytocin neurons (Armstrong et al., 2002; Bale et al., 1995; Coirini et al., 1992; de Kloet et al., 1986; Israel and Poulain, 2000; Miller et al., 1989; Patisaul et al., 2003), which may account for the higher efficacy of exogenous oxytocin in female versus male C58/J mice. The sexually dimorphic effects might also be related to sex-specific dependence on either the oxytocinergic or vasopressinergic systems, as seen in prairie voles (Cushing and Carter, 2000; Insel and Hulihan, 1995; Yamamoto et al., 2004). Taken together, these observations suggest that repeated oxytocin administration primes the oxytocin system to become more sensitive to endogenous oxytocin signaling. Because deficiencies in the oxytocin pathway have been associated with ASDs, sensitization of the oxytocin system may improve sociability in autistic people.

Considering the lack of drug therapies to ameliorate the core symptoms of ASDs, the oxytocin receptor is an attractive target, particularly for addressing the profound social deficits observed in autism. Yet, how the oxytocin system regulates social behavior is poorly understood, perhaps because this system can influence and be influenced by other neurochemical systems. For example, serotonin receptors and glutamate receptors regulate oxytocin release (Busnardo et al., 2012; Jørgensen et al., 2003; Pampillo et al., 2001; Saydoff et al., 1991). It is notable that the few drugs that exhibit prosocial efficacy in mouse models of social deficits directly or indirectly target the serotonergic system (e.g. MDMA, buspirone, and fluoxetine) (Chadman, 2011; Gould et al., 2011; Thompson et al., 2007) and the glutamatergic system (e.g. D-serine, MP-10, papaverine, GRN-529, and AMPAKINEs) (Grauer et al., 2009; Jacome et al., 2011; Labrie et al., 2008; Silverman et al., 2012a; Silverman et al., 2012b). Thus, one could speculate that an underlying mechanism for the prosocial effects of these agents is the modulation of oxytocin secretion. Conversely, oxytocin itself has been shown to influence several neurochemical systems, including the serotonergic, glutamatergic, dopaminergic, and GABAergic systems in multiple brain regions (e.g. hypothalamus, amygdala, and hippocampus) (Brussaard et al., 1996; Eaton et al., 2012; Melis et al., 2009; Ninan, 2011; Rosenfeld et al., 2011; Sala et al., 2011; Succu et al., 2011; Theodosis et al., 2006; Yoshida et al., 2009). Therefore, oxytocin treatment may stimulate a feed-forward loop through the modulation of these neurochemical systems that provide feedback input to the oxytocinergic system, which could contribute to prosocial efficacy. 
In contrast to the findings on social approach, we did not observe any sexually dimorphic effects of oxytocin administration on repetitive behavior in the C58/J model. For both male and female C58/J mice, abnormal repetitive behavior was decreased by acute, but not subchronic, treatment with oxytocin. It is possible that the dose of oxytocin utilized in the subchronic regimen was not optimal for persistent effects on repetitive behavior. Other studies examining oxytocin effects in animal models have reported bell-shaped dose response curves, with higher doses of oxytocin exhibiting less efficacy than more moderate doses (Arletti and Bertolini, 1987; Kovács et al., 1985). Further, the repetitive behavior analysis after sub-chronic oxytocin treatment was conducted at the 24-hour and 1-week time points, while the strongest prosocial oxytocin effects were observed at the 2-week time point. Evaluation of repetitive behavior at later time points could reveal the emergence of oxytocin treatment effects. Although our finding of decreased motor stereotypy following acute oxytocin treatment is in line with one clinical study in adults with autism or Asperger's syndrome (Hollander et al., 2003), an important caveat is possible effects on activity, especially sedative-like action (Uvnäs-Moberg et al., 1994). In the present study, acute oxytocin led to a significant decrease in locomotion and an increase in grooming during the test for repetitive behavior, which could have confounded drug effects on motor stereotypy. While the results from the open field test imply that the acute effects of oxytocin on motor stereotypy were not simply due to hypoactivity or anxiolytic-like effects, we observed substantial variability in these measures and a possible trend for reduced locomotion during multiple time intervals. Further research will be necessary to clarify the effects of oxytocin treatment on repetitive behavior in the $\mathrm{C} 58 / \mathrm{J}$ model, including an evaluation of doseresponse.

In conclusion, sub-chronic oxytocin treatment reverses sociability deficits in the BALB/ cByJ and C58/J mouse models of ASD-relevant phenotypes. These inbred mouse strains provide an attractive translational platform for screening drugs targeting the oxytocin signaling pathway and for investigating mechanisms underpinning the efficacy of oxytocin against core ASD symptoms. Our ongoing studies include testing the dose-dependence and longer-term persistence of oxytocin effects on social and repetitive behavior. Using these models, future studies analyzing the molecular and neurobiological changes in response to oxytocin treatment could provide important insights into social behavior and new avenues for drug discovery in ASDs and other disorders characterized by impaired social function.

\section{Acknowledgments}

Support for these studies was provided by the Department of Defense (AR1002312P1, AR1002312P2, and AR1002312P3) and the National Institute of Child Health \& Human Development (P30 HD03110). Brian L. Teng was funded by an Autism Speaks Translational Postdoctoral Fellowship (\#7952).

\section{References}

Anagnostou E, Soorya L, Chaplin W, Bartz J, Halpern D, Wasserman S, Wang AT, Pepa L, Tanel N, Kushki A. Intranasal oxytocin versus placebo in the treatment of adults with autism spectrum disorders: a randomized controlled trial. Mol Autism. 2012; 3:16. [PubMed: 23216716]

Andari E, Duhamel JR, Zalla T, Herbrecht E, Leboyer M, Sirigu A. Promoting social behavior with oxytocin in high-functioning autism spectrum disorders. Proc Natl Acad Sci USA. 2010; 107:43894394. [PubMed: 20160081]

Arletti R, Bertolini A. Oxytocin acts as an antidepressant in two animal models of depression. Life Sci. 1987; 41:1725-1730. [PubMed: 3657379]

Armstrong WE, Stern JE, Teruyama R. Plasticity in the electrophysiological properties of oxytocin neurons. Microsc Res Tech. 2002; 56:73-80. [PubMed: 11810710]

Bale TL, Dorsa DM, Johnston CA. Oxytocin receptor mRNA expression in the ventromedial hypothalamus during the estrous cycle. J Neurosci. 1995; 15:5058-5064. [PubMed: 7623134] 
Bowen MT, Carson DS, Spiro A, Arnold JC, McGregor IS. Adolescent oxytocin exposure causes persistent reductions in anxiety and alcohol consumption and enhances sociability in rats. PloS one. 2011; 6:e27237. [PubMed: 22110618]

Brodkin ES. BALB/c mice: low sociability and other phenotypes that may be relevant to autism. Behav Brain Res. 2007; 176:53-65. [PubMed: 16890300]

Brodkin ES, Hagemann A, Nemetski SM, Silver LM. Social approach-avoidance behavior of inbred mouse strains towards DBA/2 mice. Brain Res. 2004; 1002:151-157. [PubMed: 14988045]

Brussaard AB, Kits KS, De Vlieger TA. Postsynaptic mechanism of depression of GABAergic synapses by oxytocin in the supraoptic nucleus of immature rat. J Physiol. 1996; 497:495-507. [PubMed: 8961190]

Busnardo C, Crestani CC, Resstel LBM, Tavares RF, Antunes-Rodrigues J, Corrêa FMA. Ionotropic glutamate receptors in hypothalamic paraventricular and supraoptic nuclei mediate vasopressin and oxytocin release in unanesthetized rats. Endocrinology. 2012; 153:2323-2331. [PubMed: 22396452]

Carrasco M, Volkmar FR, Bloch MH. Pharmacologic treatment of repetitive behaviors in autism spectrum disorders: evidence of publication bias. Pediatrics. 2012; 129:e1301-e1310. [PubMed: 22529279]

CDC. Prevalence of Autism Spectrum Disorders - Autism and Developmental Disabilities Monitoring Network, 14 Sites, United States, 2008. MMWR. 2012; 61:1-19.

Chadman KK. Fluoxetine but not risperidone increases sociability in the BTBR mouse model of autism. Pharmacol Biochem Behav. 2011; 97:586-594. [PubMed: 20863848]

Chini B, Manning M. Agonist selectivity in the oxytocin/vasopressin receptor family: new insights and challenges. Biochem Soc Trans. 2007; 35:737-741. [PubMed: 17635137]

Coirini H, Johnson AE, Schumacher M, McEwen BS. Sex differences in the regulation of oxytocin receptors by ovarian steroids in the ventromedial hypothalamus of the rat. Neuroendocrinology. 1992; 55:269-275. [PubMed: 1323800]

Cushing BS, Carter CS. Peripheral pulses of oxytocin increase partner preferences in female, but not male, prairie voles. Horm Behav. 2000; 37:49-56. [PubMed: 10712858]

de Kloet ER, Voorhuis DA, Boschma Y, Elands J. Estradiol modulates density of putative'oxytocin receptors' in discrete rat brain regions. Neuroendocrinology. 1986; 44:415-421. [PubMed: 3029614]

Eaton JL, Roache L, Nguyen KN, Cushing BS, Troyer E, Papademetriou E, Raghanti MA. Organizational effects of oxytocin on serotonin innervation. Dev Psychobiol. 2012; 54:92-97. [PubMed: 21594870]

Elsabbagh M, Divan G, Koh YJ, Kim YS, Kauchali S, Marcín C, Montiel-Nava C, Patel V, Paula CS, Wang C. Global prevalence of autism and other pervasive developmental disorders. Autism Res. 2012; 5:160-179. [PubMed: 22495912]

Feifel D, Macdonald K, Nguyen A, Cobb P, Warlan H, Galangue B, Minassian A, Becker O, Cooper J, Perry W. Adjunctive intranasal oxytocin reduces symptoms in schizophrenia patients. Biol Psychiatry. 2010; 68:678-680. [PubMed: 20615494]

Fiorino DF, Phillips AG. Facilitation of sexual behavior in male rats following d-amphetamineinduced behavioral sensitization. Psychopharmacology. 1999; 142:200-208. [PubMed: 10102773]

Gould GG, Hensler JG, Burke TF, Benno RH, Onaivi ES, Daws LC. Density and function of central serotonin (5-HT) transporters, 5-HT1A and 5-HT2A receptors, and effects of their targeting on BTBR T+ tf/J mouse social behavior. J Neurochem. 2011; 116:291-303. [PubMed: 21070242]

Grauer SM, Pulito VL, Navarra RL, Kelly MP, Kelley C, Graf R, Langen B, Logue S, Brennan J, Jiang L. Phosphodiesterase 10A inhibitor activity in preclinical models of the positive, cognitive, and negative symptoms of schizophrenia. J Pharmacol Exp Ther. 2009; 331:574-590. [PubMed: 19661377]

Guastella AJ, Einfeld SL, Gray KM, Rinehart NJ, Tonge BJ, Lambert TJ, Hickie IB. Intranasal oxytocin improves emotion recognition for youth with autism spectrum disorders. Biol Psychiatry. 2010; 67:692-694. [PubMed: 19897177]

Higashida H, Yokoyama S, Huang JJ, Liu L, Ma WJ, Akther S, Higashida C, Kikuchi M, Minabe Y, Munesue T. Social memory, amnesia, and autism: Brain oxytocin secretion is regulated by NAD< 
sup $>+</$ sup $>$ metabolites and single nucleotide polymorphisms of CD38. Neurochem Int. 2012; 61:828-838. [PubMed: 22366648]

Hollander E, Bartz J, Chaplin W, Phillips A, Sumner J, Soorya L, Anagnostou E, Wasserman S. Oxytocin increases retention of social cognition in autism. Biol Psychiatry. 2007; 61:498-503. [PubMed: 16904652]

Hollander E, Novotny S, Hanratty M, Yaffe R, DeCaria CM, Aronowitz BR, Mosovich S. Oxytocin infusion reduces repetitive behaviors in adults with autistic and Asperger's disorders. Neuropsychopharmacology. 2003; 28:193-198. [PubMed: 12496956]

Insel TR. The challenge of translation in social neuroscience: a review of oxytocin, vasopressin, and affiliative behavior. Neuron. 2010; 65:768-779. [PubMed: 20346754]

Insel TR, Hulihan TJ. A gender-specific mechanism for pair bonding: oxytocin and partner preference formation in monogamous voles. Behav Neurosci. 1995; 109:782-789. [PubMed: 7576222]

Israel JM, Poulain DA. $17 \beta$-Oestradiol modulates in vitro electrical properties and responses to kainate of oxytocin neurones in lactating rats. J Physiol. 2000; 524:457-470. [PubMed: 10766926]

Jacome LF, Burket JA, Herndon AL, Cannon WR, Deutsch SI. D-serine improves dimensions of the sociability deficit of the genetically-inbred Balb/c mouse strain. Brain Res Bull. 2011; 84:12-16. [PubMed: 21056638]

Johns JM, Nelson CJ, Meter KE, Lubin DA, Couch CD, Ayers A, Walker CH. Dose-dependent effects of multiple acute cocaine injections on maternal behavior and aggression in Sprague-Dawley rats. Dev Neurosci. 1998; 20:525-532. [PubMed: 9858841]

Jørgensen H, Riis M, Knigge U, Kjaer A, Warberg J. Serotonin receptors involved in vasopressin and oxytocin secretion. J Neuroendocrinol. 2003; 15:242-249. [PubMed: 12588512]

Kang YS, Park JH. Brain uptake and the analgesic effect of oxytocin--its usefulness as an analgesic agent. Arch Pharm Res. 2000; 23:391-395. [PubMed: 10976589]

Kikusui T, Nakanishi K, Nakagawa R, Nagasawa M, Mogi K, Okanoya K. Cross fostering experiments suggest that mice songs are innate. PloS one. 2011; 6:e17721. [PubMed: 21408017]

Kim DH, Jung JS, Song DK, Suh HW, Huh SO, Kim YH. Intracerebroventricular injection-induced increase in plasma corticosterone levels in the mouse: a stress model. J Pharmacol Toxicol Methods. 1998; 39:71-73. [PubMed: 9694164]

Kovács GL, Faludi M, Telegdy G. Oxytocin diminishes heroin tolerance in mice. Psychopharmacology. 1985; 86:377-379. [PubMed: 3929307]

Labrie V, Lipina T, Roder JC. Mice with reduced NMDA receptor glycine affinity model some of the negative and cognitive symptoms of schizophrenia. Psychopharmacology. 2008; 200:217-230. [PubMed: 18597079]

Lundeberg T, Uvnäs-Moberg K, Ågren G, Bruzelius G. Anti-nociceptive effects of oxytocin in rats and mice. Neurosci Lett. 1994; 170:153-157. [PubMed: 8041495]

McDougle CJ, Scahill L, Aman MG, McCracken JT, Tierney E, Davies M, Arnold LE, Posey DJ, Martin A, Ghuman J. Risperidone for the core symptom domains of autism: results from the study by the autism network of the research units on pediatric psychopharmacology. Am J Psychiatry. 2005; 162:1142-1148. [PubMed: 15930063]

McPheeters ML, Warren Z, Sathe N, Bruzek JL, Krishnaswami S, Jerome RN, Veenstra-Vanderweele J. A systematic review of medical treatments for children with autism spectrum disorders. Pediatrics. 2011; 127:e1312-e1321. [PubMed: 21464191]

Melis MR, Succu S, Sanna F, Boi A, Argiolas A. Oxytocin injected into the ventral subiculum or the posteromedial cortical nucleus of the amygdala induces penile erection and increases extracellular dopamine levels in the nucleus accumbens of male rats. Eur J Neurosci. 2009; 30:1349-1357. [PubMed: 19769589]

Meyer-Lindenberg A, Domes G, Kirsch P, Heinrichs M. Oxytocin and vasopressin in the human brain: social neuropeptides for translational medicine. Nat Rev Neurosci. 2011; 12:524-538. [PubMed: 21852800]

Miller FD, Ozimek G, Milner RJ, Bloom FE. Regulation of neuronal oxytocin mRNA by ovarian steroids in the mature and developing hypothalamus. Proc Natl Acad Sci USA. 1989; 86:24682472. [PubMed: 2928343] 
Morin V, Del Castillo JR, Authier S, Ybarra N, Otis C, Gauvin D, Gutkowska J, Troncy E. Evidence for non-linear pharmacokinetics of oxytocin in anesthetizetized rat. J Pharm Pharm Sci. 2008; 11:12-24. [PubMed: 19183510]

Moy SS, Breese GR. Phencyclidine supersensitivity in rats with neonatal dopamine loss. Psychopharmacology. 2002; 161:255-262. [PubMed: 12021828]

Moy SS, Nadler JJ, Perez A, Barbaro RP, Johns JM, Magnuson TR, Piven J, Crawley JN. Sociability and preference for social novelty in five inbred strains: an approach to assess autistic-like behavior in mice. Genes Brain Behav. 2004; 3:287-302. [PubMed: 15344922]

Moy SS, Nadler JJ, Young NB, Nonneman RJ, Segall SK, Andrade GM, Crawley JN, Magnuson TR. Social approach and repetitive behavior in eleven inbred mouse strains. Behav Brain Res. 2008; 191:118-129. [PubMed: 18440079]

Moy SS, Nadler JJ, Young NB, Perez A, Holloway LP, Barbaro RP, Barbaro JR, West LM, Threadgill DW, Lauder JM. Mouse behavioral tasks relevant to autism: phenotypes of ten inbred strains. Behav Brain Res. 2007; 176:4-20. [PubMed: 16971002]

Nadler JJ, Moy SS, Dold G, Trang D, Simmons N, Perez A, Young NB, Barbaro RP, Piven J, Magnuson TR. Automated apparatus for quantitation of social approach behaviors in mice. Genes Brain Behav. 2004; 3:303-314. [PubMed: 15344923]

Nazeer A, Ghaziuddin M. Autism spectrum disorders: clinical features and diagnosis. Pediatr Clin North Am. 2012; 59:19-25. [PubMed: 22284790]

Ninan I. Oxytocin suppresses basal glutamatergic transmission but facilitates activity-dependent synaptic potentiation in the medial prefrontal cortex. J Neurochem. 2011; 119:324-331. [PubMed: 21848811]

Pampillo M, del Carmen DM, Duvilanski B, Rettori V, Seilicovich A, Lasaga M. Differential effects of glutamate agonists and D-aspartate on oxytocin release from hypothalamus and posterior pituitary of male rats. Endocrine. 2001; 15:309-315. [PubMed: 11762705]

Panksepp JB, Jochman KA, Kim JU, Koy JJ, Wilson ED, Chen Q, Wilson CR, Lahvis GP. Affiliative behavior, ultrasonic communication and social reward are influenced by genetic variation in adolescent mice. PloS one. 2007; 2:e351. [PubMed: 17406675]

Patisaul HB, Scordalakes EM, Young LJ, Rissman EF. Oxytocin, but not oxytocin receptor, is regulated by oestrogen receptor beta in the female mouse hypothalamus. J Neuroendocrinol. 2003; 15:787-793. [PubMed: 12834440]

Pedersen CA, Gibson CM, Rau SW, Salimi K, Smedley KL, Casey RL, Leserman J, Jarskog LF, Penn DL. Intranasal oxytocin reduces psychotic symptoms and improves Theory of Mind and social perception in schizophrenia. Schizophr Res. 2011; 132:50-53. [PubMed: 21840177]

Ring RH, Malberg JE, Potestio L, Ping J, Boikess S, Luo B, Schechter LE, Rizzo S, Rahman Z, Rosenzweig-Lipson S. Anxiolytic-like activity of oxytocin in male mice: behavioral and autonomic evidence, therapeutic implications. Psychopharmacology. 2006; 185:218-225. [PubMed: 16418825]

Rosenfeld AJ, Lieberman JA, Jarskog LF. Oxytocin, dopamine, and the amygdala: a neurofunctional model of social cognitive deficits in schizophrenia. Schizophr Bull. 2011; 37:1077-1087. [PubMed: 20308198]

Ryan BC, Young NB, Crawley JN, Bodfish JW, Moy SS. Social deficits, stereotypy and early emergence of repetitive behavior in the C58/J inbred mouse strain. Behav Brain Res. 2010; 208:178-188. [PubMed: 19941908]

Sala M, Braida D, Lentini D, Busnelli M, Bulgheroni E, Capurro V, Finardi A, Donzelli A, Pattini L, Rubino T. Pharmacologic rescue of impaired cognitive flexibility, social deficits, increased aggression, and seizure susceptibility in oxytocin receptor null mice: a neurobehavioral model of autism. Biol Psychiatry. 2011; 69:875-882. [PubMed: 21306704]

Sankoorikal GMV, Kaercher KA, Boon CJ, Lee JK, Brodkin ES. A mouse model system for genetic analysis of sociability: C57BL/6J versus BALB/cJ inbred mouse strains. Biol Psychiatry. 2006; 59:415-423. [PubMed: 16199013]

Saydoff JA, Rittenhouse PA, van de Kar LD, Brownfield MS. Enhanced serotonergic transmission stimulates oxytocin secretion in conscious male rats. J Pharmacol Exp Ther. 1991; 257:95-99. [PubMed: 1850481] 
Schorscher-Petcu A, Sotocinal S, Ciura S, Dupré A, Ritchie J, Sorge RE, Crawley JN, Hu SB, Nishimori K, Young LJ. Oxytocin-induced analgesia and scratching are mediated by the vasopressin-1A receptor in the mouse. J Neurosci. 2010; 30:8274-8284. [PubMed: 20554879]

Silverman, JL.; Oliver, CF.; Karras, MN.; Gastrell, PT.; Crawley, JN. AMPAKINE enhancement of social interaction in the BTBR mouse model of autism. Neuropharmacology. 2012a. http:// dx.doi.org/10.1016/j.neuropharm.2012.1007.1013

Silverman JL, Smith DG, Rizzo SJS, Karras MN, Turner SM, Tolu SS, Bryce DK, Smith DL, Fonseca K, Ring RH, Crawley JN. Negative allosteric modulation of the mGluR5 receptor reduces repetitive behaviors and rescues social deficits in mouse models of autism. Sci Transl Med. 2012b; 4:131ra151.

Stachnik JM, Nunn-Thompson C. Use of atypical antipsychotics in the treatment of autistic disorder. Ann Pharmacother. 2007; 41:626-634. [PubMed: 17389666]

Striepens N, Kendrick KM, Maier W, Hurlemann R. Prosocial effects of oxytocin and clinical evidence for its therapeutic potential. Front Neuroendocrinol. 2011; 32:426-450. [PubMed: 21802441]

Succu S, Sanna F, Argiolas A, Melis MR. Oxytocin injected into the hippocampal ventral subiculum induces penile erection in male rats by increasing glutamatergic neurotransmission in the ventral tegmental area. Neuropharmacology. 2011; 61:181-188. [PubMed: 21496460]

Theodosis DT. Oxytocin-secreting neurons: A physiological model of morphological neuronal and glial plasticity in the adult hypothalamus. Front Neuroendocrinol. 2002; 23:101-135. [PubMed: 11906204]

Theodosis DT, Koksma JJ, Trailin A, Langle SL, Piet R, Lodder JC, Timmerman J, Mansvelder H, Poulain DA, Oliet SH. Oxytocin and estrogen promote rapid formation of functional GABA synapses in the adult supraoptic nucleus. Mol Cell Neurosci. 2006; 31:785-794. [PubMed: 16488155]

Thompson MR, Callaghan PD, Hunt GE, Cornish JL, McGregor IS. A role for oxytocin and 5-HT (1A) receptors in the prosocial effects of 3, 4 methylenedioxymethamphetamine (" ecstasy"). Neuroscience. 2007; 146:509-514. [PubMed: 17383105]

Uvnäs-Moberg K, Ahlenius S, Hillegaart V, Alster P. High doses of oxytocin cause sedation and low doses cause an anxiolytic-like effect in male rats. Pharmacol Biochem Behav. 1994; 49:101-106. [PubMed: 7816858]

Yamakage M, Tsujiguchi N, Chen X, Kamada Y, Namiki A. Sevoflurane inhibits contraction of uterine smooth muscle from pregnant rats similarly to halothane and isoflurane. Can J Anaesth. 2002; 49:62-66. [PubMed: 11782330]

Yamamoto Y, Cushing BS, Kramer KM, Epperson PD, Hoffman GE, Carter CS. Neonatal manipulations of oxytocin alter expression of oxytocin and vasopressin immunoreactive cells in the paraventricular nucleus of the hypothalamus in a gender-specific manner. Neuroscience. 2004; 125:947-955. [PubMed: 15120854]

Yoshida M, Takayanagi Y, Inoue K, Kimura T, Young LJ, Onaka T, Nishimori K. Evidence that oxytocin exerts anxiolytic effects via oxytocin receptor expressed in serotonergic neurons in mice. J Neurosci. 2009; 29:2259-2271. [PubMed: 19228979] 
- Prosocial effects of oxytocin were dependent on dose regimen, genotype, and sex

- Sub-chronic, but not acute, oxytocin treatment regimen led to increased sociability

- Acute oxytocin decreased repetitive behavior, but not activity in an open field

- $\mathrm{BALB} / \mathrm{cByJ}$ and $\mathrm{C} 58 / \mathrm{J}$ are valuable preclinical tools to screen prosocial drugs 


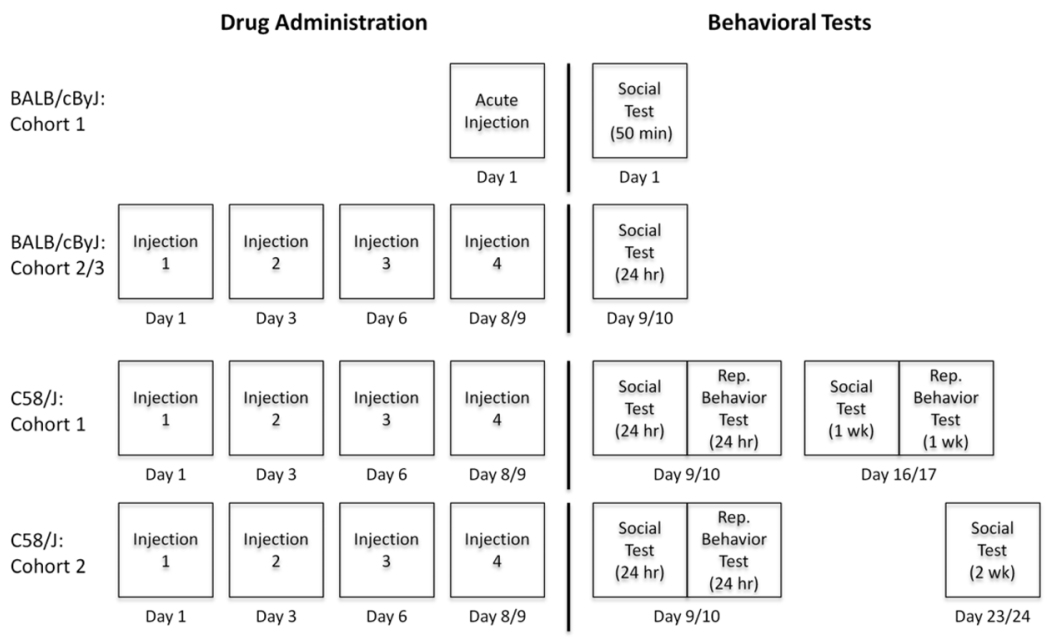

Fig. 1. Experimental timelines for the acute and sub-chronic oxytocin regimens, and behavioral tests in BALB/cByJ and C58/J mice

The acute regimen was a single-dose of vehicle or oxytocin $(1.0 \mathrm{mg} / \mathrm{kg})$ administered 50 minutes before behavioral testing. The sub-chronic regimen consisted of four doses of either vehicle or oxytocin $(1.0 \mathrm{mg} / \mathrm{kg})$ across an 8-9 day period, with at least 48 hours between each IP injection. Sociability (Social) or repetitive (Rep.) behavior testing occurred on the indicated days. C58/J Cohorts 3 and 4 are not shown. 

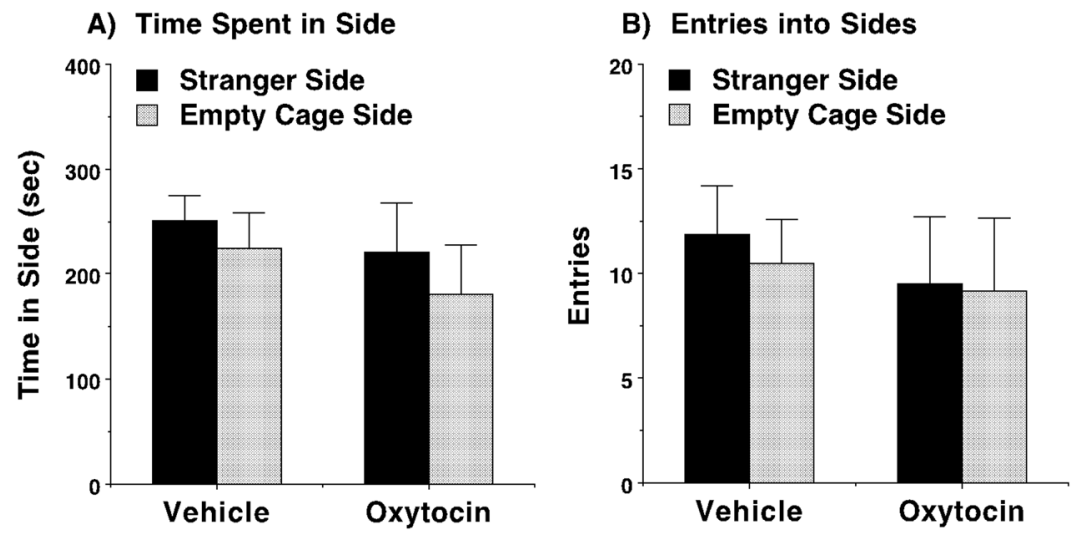

Fig. 2. Lack of prosocial effects of oxytocin with acute treatment in male BALB/cByJ mice Oxytocin $(1.0 \mathrm{mg} / \mathrm{kg})$ was administered 50 minutes before evaluating social approach in the three-chambered choice test. Data shown are means $(+$ SEM) for 6 mice per treatment group. 
A) Cohort 2

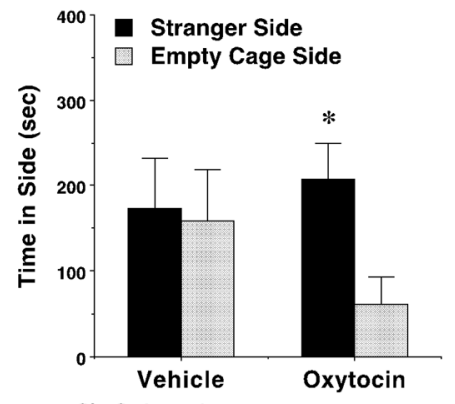

C) Cohort 2

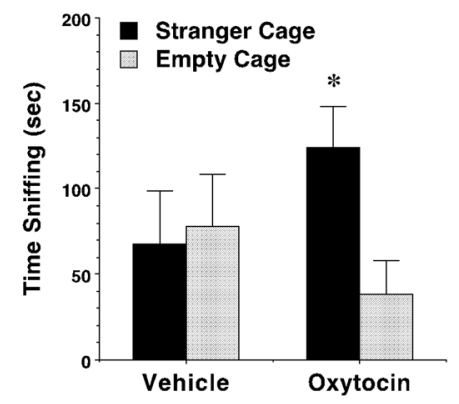

E) Cohort 2

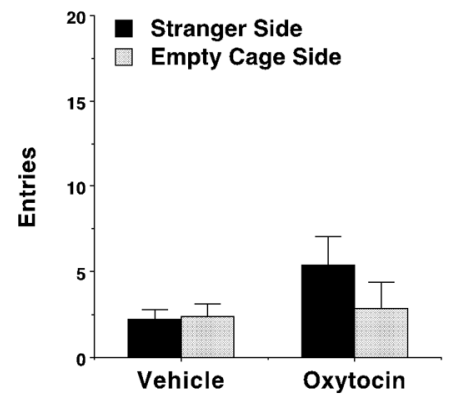

B) Cohort 3

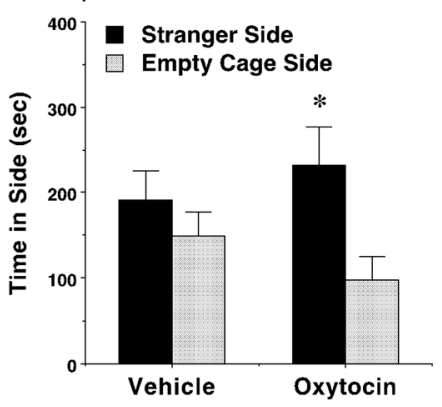

D) Cohort 3

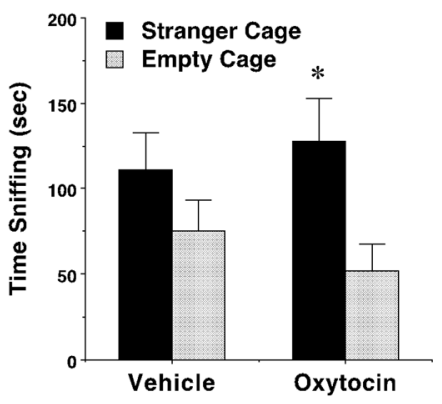

F) Cohort 3

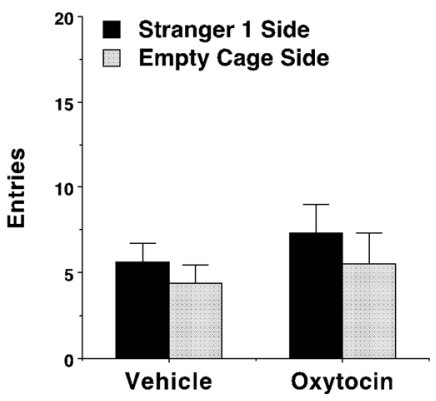

Fig. 3. Prosocial effects of oxytocin with sub-chronic treatment in male BALB/cByJ mice The sub-chronic regimen consisted of four doses of either vehicle or oxytocin $(1.0 \mathrm{mg} / \mathrm{kg})$ across an 8-9 day period, with at least 48 hours between each IP injection. Subjects were tested for sociability in the three-chambered choice test 24 hours following the final dose. $\mathrm{N}=12-18$ per group. Sniffing data are missing from two mice in Cohort 2 due to experimenter error. ${ }^{*} \mathrm{p}<0.05$, within-group comparison. 


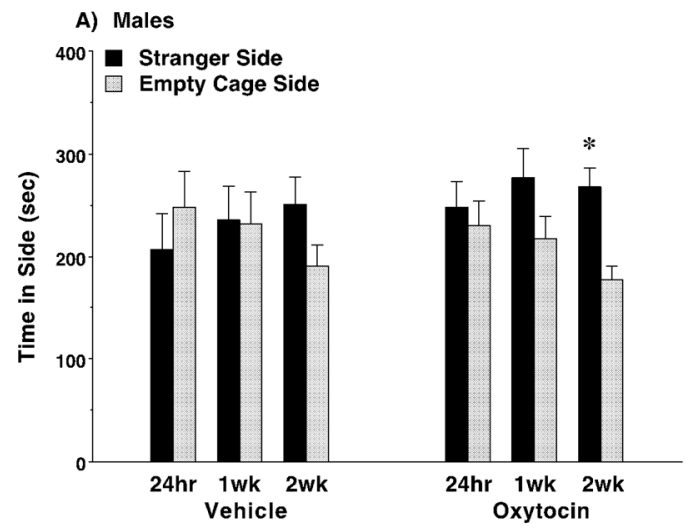

B) Females

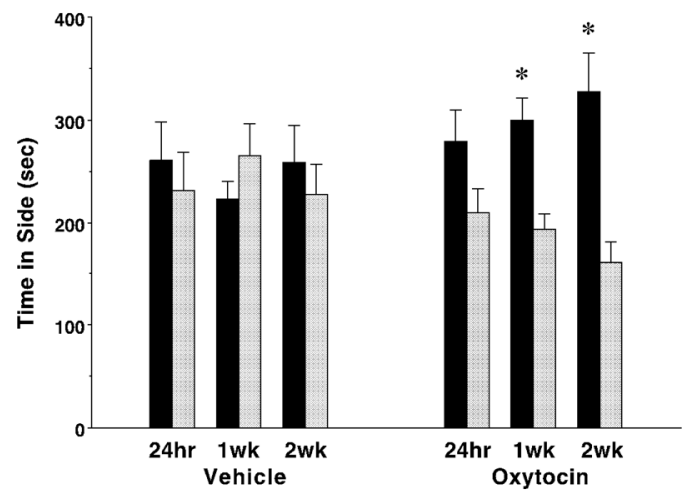

Fig. 4. Prosocial effects of sub-chronic oxytocin in $\mathrm{C} 58 / \mathrm{J}$ mice

The sub-chronic regimen consisted of four doses of either vehicle or oxytocin $(1.0 \mathrm{mg} / \mathrm{kg})$ across an 8-9 day period, with at least 48 hours between each IP injection. Subjects were tested for sociability 24 hours following the final dose ( $N=16$ per sex, per treatment). Half of the mice were further tested 1 week (1wk) after the sub-chronic oxytocin regimen, and the remaining mice were tested 2 weeks $(2 \mathrm{wk})$ following treatment. Data were lost for one female subject at the 24 -hour time point due to equipment failure. ${ }^{*} \mathrm{p}<0.05$, withintreatment group comparison. 


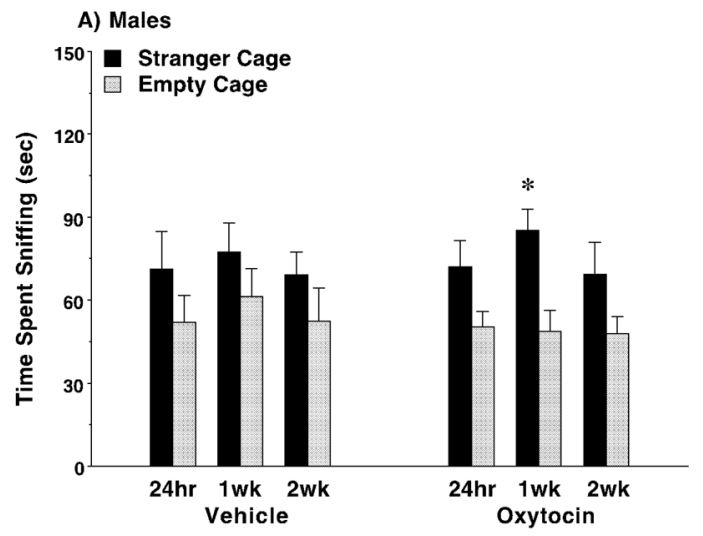

B) Females

${ }^{150}$ Stranger Cage

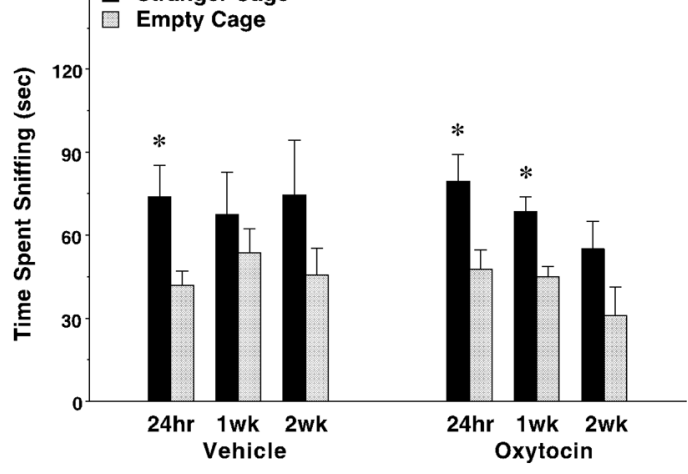

Fig. 5. Effects of sub-chronic oxytocin on time spent sniffing the stranger cage or empty cage The sub-chronic regimen consisted of four doses of either vehicle or oxytocin $(1.0 \mathrm{mg} / \mathrm{kg})$ across an 8-9 day period, with at least 48 hours between each IP injection. Subjects were tested for sociability 24 hours following the final dose $(\mathrm{N}=16$ per sex, per treatment). Half of the mice were further tested 1 week ( $1 \mathrm{wk}$ ) after the sub-chronic oxytocin regimen, and the remaining mice were tested 2 weeks $(2 \mathrm{wk})$ following treatment. $* \mathrm{p}<0.05$, within-treatment group comparison. 


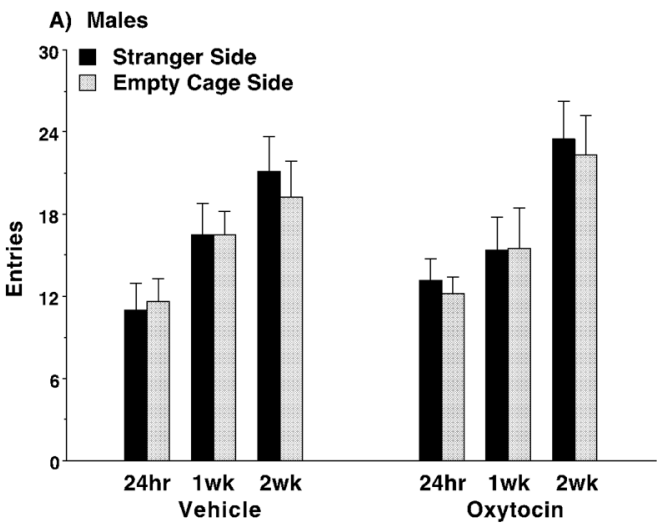

B) Females

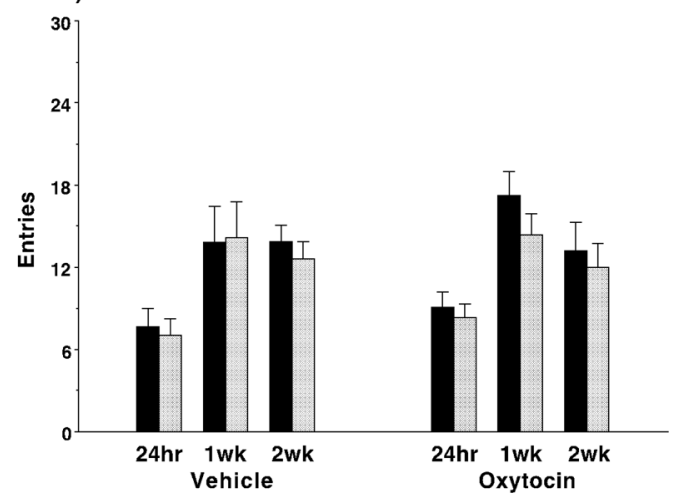

Fig. 6. No effects of sub-chronic oxytocin on number of entries in $\mathbf{C 5 8} / \mathbf{J}$ mice

The sub-chronic regimen consisted of four doses of either vehicle or oxytocin $(1.0 \mathrm{mg} / \mathrm{kg})$ across an 8-9 day period, with at least 48 hours between each IP injection. Subjects were tested for sociability 24 hours following the final dose ( $N=16$ per sex, per treatment). Half of the mice were further tested 1 week (1wk) after the end of the oxytocin regimen, and the remaining mice were tested 2 weeks ( 2 wk) following the final dose. Data were lost for one female subject at the 24-hour time point due to equipment failure. 

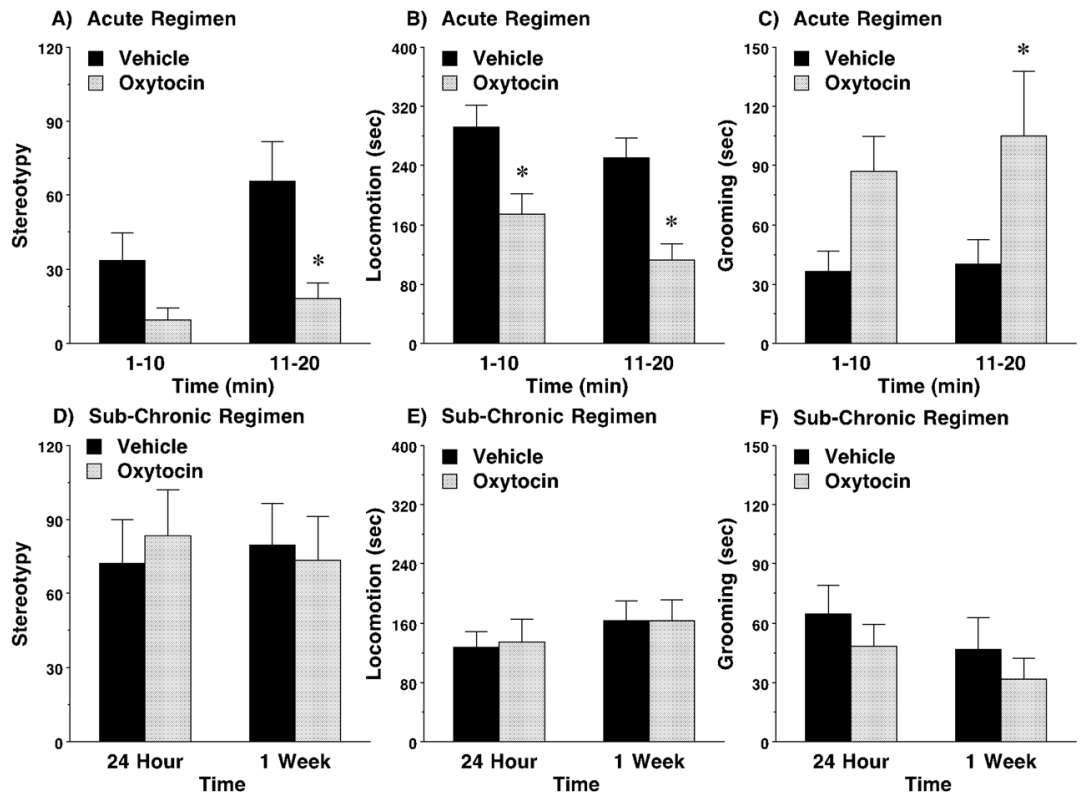

Fig. 7. Effects of acute and sub-chronic oxytocin on motor stereotypy in C58/J mice A-C) Oxytocin $(1 \mathrm{mg} / \mathrm{kg})$ or vehicle was administered 50 minutes before a 20 -minute session. Means (+ SEM) are presented for the first and second 10-minute intervals. Data for five mice with zero levels of stereotypy after vehicle treatment were not included.

Remaining number of mice were $\mathrm{N}=16$ (9 males and 7 females). D-F) The sub-chronic regimen consisted of four doses of either vehicle or oxytocin $(1.0 \mathrm{mg} / \mathrm{kg})$ across an 8-9 day period, with at least 48 hours between each IP injection. Subjects were first tested for sociability 24 hours or 1 week following the final dose, and then given a 30-minute session for repetitive behavior following each test. Data are presented for the final 10 minutes. * $\mathrm{p}<0.05$. 


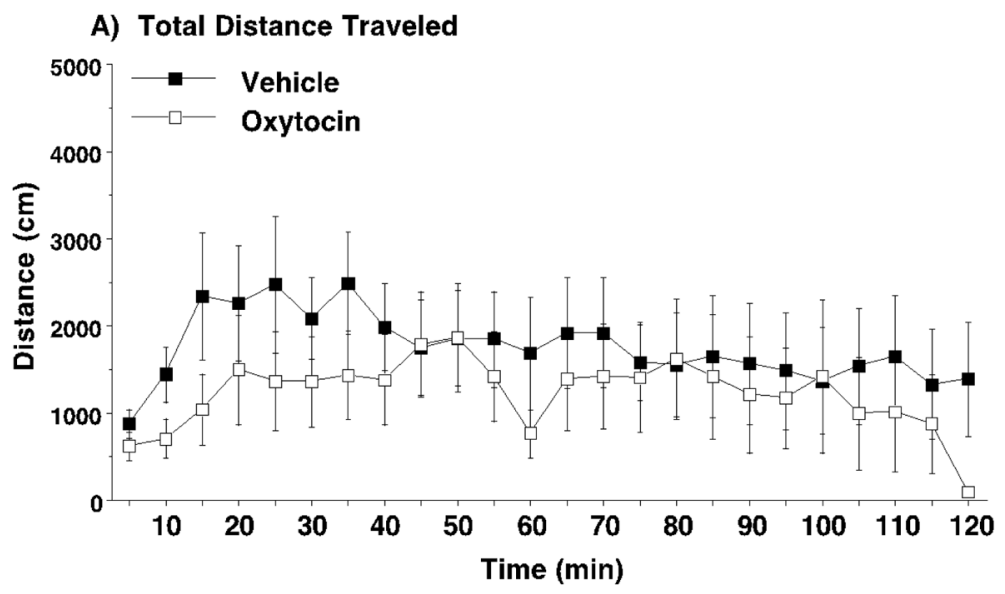

B) Time in Center Region

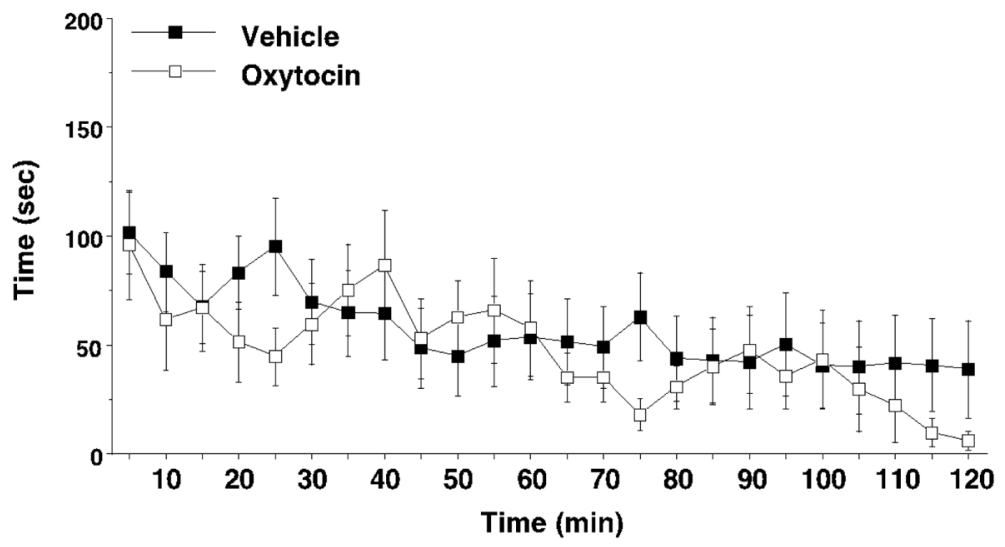

Fig. 8. Lack of oxytocin effects on activity and anxiety-like behavior in an open field test Oxytocin $(1.0 \mathrm{mg} / \mathrm{kg})$ or vehicle was administered immediately before the start of a 2-hour open field test. Data are means (+ SEM) for $16 \mathrm{C} 58 / \mathrm{J}$ mice ( 8 males and 8 females), each tested once with vehicle and once with oxytocin, using a crossover design. 